\title{
SMALL-SCALE SPATIAL PATTERNS OF TWO TERRICOLOUS LICHENS IN A CONIFER PLANTATION
}

\author{
SeVGi, E. ${ }^{1}-$ YILMAZ, O. Y. ${ }^{2 *}-$ SeVGI, O. ${ }^{3}$ \\ ${ }^{l}$ Department of Pharmaceutical Botany, Faculty of Pharmacy, Bezmialem Vakif University, \\ Istanbul, Turkey \\ ${ }^{2}$ Department of Surveying and Cadastre, Faculty of Forestry, Istanbul University-Cerrahpaşa, \\ Istanbul, Turkey \\ ${ }^{3}$ Department of Soil Science and Ecology, Faculty of Forestry, Istanbul University-Cerrahpaşa, \\ Istanbul, Turkey \\ ${ }^{*}$ Corresponding author \\ e-mail:yilmazy@istanbul.edu.tr \\ (Received $9^{\text {th }}$ Dec 2019; accepted $23^{\text {rd }}$ Mar 2020)
}

\begin{abstract}
Various studies have been conducted on the factors affecting the spatial distribution of terricolous lichen species at regional and landscape scales, yet not on small-scales. In our study, the distribution of lichens was obtained by objective classification and spatial analysis of RGB camera images taken from two different heights by an unmanned aerial vehicle at a reforested area of $1575 \mathrm{~m}^{2}$. Black pine and cypress are species that have been introduced, while the, native species are oak and mock privet. The total area covered by Cladonia rangiformis Hoffm., $\left(26.17 \mathrm{~m}^{2}\right)$ in the study area was 5 times higher than that covered by the Cladonia foliacea (Huds.) Willd. $\left(5.01 \mathrm{~m}^{2}\right)$. These species were found to be located mostly to the north and sometimes at the east of the tree species. C. rangiformis was found under the crown projection area of cypress; however, no such result has been found for black pine, mock privet, and oak. Therefore, tree species affect the distribution of terricolous lichen species. The patch sizes of both of these lichen species fit the power law distribution and demonstrate inhomogeneous spatial distribution in the area. C. rangiformis and $C$. foliacea patch size classes generally clustered at short distance (2-2.5 meters) and demonstrated regular distribution beyond this distance.
\end{abstract}

Keywords: directional interaction, inhomogeneous distribution, patch-size distribution, unmanned aerial vehicles, Cladonia

\section{Introduction}

Lichens can grow on human-made materials such as fences, tombstones, walls, surfaces of wooden or concrete buildings, just as they can on many natural substrates (Aptroot and James, 2002). The classification of lichens is sometimes based on these substrates; hence the lichens examined in this study are named terricolous lichens since they are located on the ground (Purvis et al., 1992).

The saxicolous lichens on rocks can affect the soil formation process both physically and chemically by weathering the rocks with the acids they produce (Chen et al., 2000; Adamo et al., 2002; Sevgi and Makineci, 2005). Similarly, terricolous lichens contribute to soil formation by changing the physical and chemical properties of the soil by covering it and releasing lichen acids (Asta et al., 2001; Maestre et al., 2011; Gypser et al., 2015; Jackson, 2015). For instance, the terricolous lichens Cladonia rangiformis Hoffm., and Peltigera neckeri Hepp ex Müll. affect soil mineralization and bacteria growth with the secondary metabolites they produce (Akpinar et al., 2009).

Some studies have been carried out on biological soil crusts (biocrust), including terricolous lichens (Eldridge, 1996, 1999; Martínez et al., 2006; Ochoa-Hueso and 
Manrique, 2011; Ochoa-Hueso et al., 2011, 2017; Pietrasiak et al., 2011; ConcostrinaZubiri et al., 2014, 2018; Gypser et al., 2015). Terricolous lichen cover is positively related to organic carbon, nitrogen, and aggregate stability in soil (Rai and Upreti, 2014). Terricolous lichens take place in different habitats as an important component of the ecosystem and are an indicator of habitat heterogeneity (Will-Wolf et al., 2002a). Besides general distribution in arid, semi-arid ecosystems or cold climate conditions (Eldridge, 1996; Zouaoui et al., 2014), terricolous lichens also prefer the gaps in shrublands and forests in Mediterranean ecosystems (Loppi et al., 2004; Ochoa-Hueso et al., 2011).

Terricolous lichen species require comparatively longer time for dispersal and establishment in the ecosystem (Zouaoui et al., 2014). Elevation and soil type are the leading factors affecting the occurrence of terricolous lichens in large areas (Will-Wolf et al., 2002b; Bowker et al., 2006; Zouaoui et al., 2014). It is also stated that gypsiferous soil is also rich in terms of the diversity of terricolous lichen (Concostrina-Zubiri et al., 2014). In a study conducted in arid and semi-arid ecosystem in Australia, the presence and diversity of terricolous lichen species contributing to the soil crusts is explained through landscape types with non-calcareous soils (Eldridge, 1996). A positive relationship exists between soil $\mathrm{pH}, \mathrm{Fe}, \mathrm{Ca}$ and spatial distribution of lichens and mosses forming soil crusts in the gaps of kermes oak scrubs in semi-arid Spain has been determined (Ochoa-Hueso et al., 2011). The species diversity of terricolous lichen communities of Northern Italy grasslands depends on soil $\mathrm{pH}$, light, and humidity requirements of lichen species (Gheza et al., 2016). Especially some terricolous lichens (Cladonia spp.) are limited by light compared to mosses (Tilk et al., 2018).

Unlike studies on factors affecting regional and landscape-level distribution of terricolous lichens, (Pietrasiak et al., 2011; Nelson et al., 2013; Concostrina-Zubiri et al., 2018) there are limited papers on understanding their spatial distribution in small-scale. In the steppe of south-eastern Spain, the microsite created by Stipa tenacissima L. may alter the small-scale spatial pattern of Cladonia convoluta (Lam.) Anders and Squamarina cartilaginea (With.) P. James (Maestre, 2003).

Remote sensing data has been used for determining lichens and biocrusts on a regional scale at deserts and arid areas (Chen, 2005), badlands (Rodríguez-Caballero, 2014), and drylands (Panigada, 2019). RGB, NIR, and hyperspectral images acquired using terrestrial and aerial photography, which are lately often used in other ecology studies, have also been used in lichen studies (Hinchliffe, 2017). However, to the best of our knowledge, this study represents the first application of aerial images in lichen studies at small-scale.

In this study, determining the spatial distribution of terricolous lichens on a small-scale with the RGB images captured by an unmanned aerial vehicle at a reforested degraded forest area was aimed. According to the hypothesis of this study lichen species are expected to a) be distributed inhomogeneously, b) cluster in the area, c) attract each other interspecifically. Lichen size classes are anticipated to fit power law distribution. Determining the effects of tree species, distance from trees, and azimuth of lichen patches cluster centroids on the spatial distribution of terricolous lichens are other objectives of the study.

\section{Materials and methods}

\section{Study area}

The study area is located in Değirmenköy (Istanbul), northwest Turkey (latitude; $41^{\circ} 08^{\prime} 11^{\prime \prime}$ and longitude; $28^{\circ} 03^{\prime} 30^{\prime \prime}$ ) at an altitude of $200 \mathrm{~m}$ a.s.l., and the distance 
from the sea is $9 \mathrm{~km}$. Mean annual precipitation is $509 \mathrm{~mm}$, and mean annual temperature is $16^{\circ} \mathrm{C}$. Presence of summer drought and drops in precipitation in winter show that mediterranean climate is dominant in the area. In 1983, the degraded forest area was reforested with mainly black pine, and cypress trees were planted as road buffer zone. While black pine (Pinus nigra J. F. Arnold) and cypress (Cupressus sempervirens L.) are species planted into the field, native species are oaks (Quercus spp.) and mock privet (Phillyrea latifolia L.). Some of the cypress species in the area were cut in 2018 (20 trees) and 2013-2014 (32 trees).

The study area is $1575 \mathrm{~m}^{2}$ and has a near flat topographic structure (Figure 1). In the study area there are 12 black pines, 102 cypresses, 44 oaks, and 29 mock privets (Table 1). Black pine is present only along the east side of the area. Among the reforestation species, blackpine has mean height $7.58 \mathrm{~m}$ and cypress has $7.56 \mathrm{~m}$, while among the natural species oak has mean height $2.42 \mathrm{~m}$ and mock privet $1.70 \mathrm{~m}$. Mean crown projection areas of the trees were $12.01 \mathrm{~m}^{2}$ for black pine, $5.68 \mathrm{~m}^{2}$ for cypress, $4.46 \mathrm{~m}^{2}$ for oak, and $3.55 \mathrm{~m}^{2}$ for mock privet (Table 1).
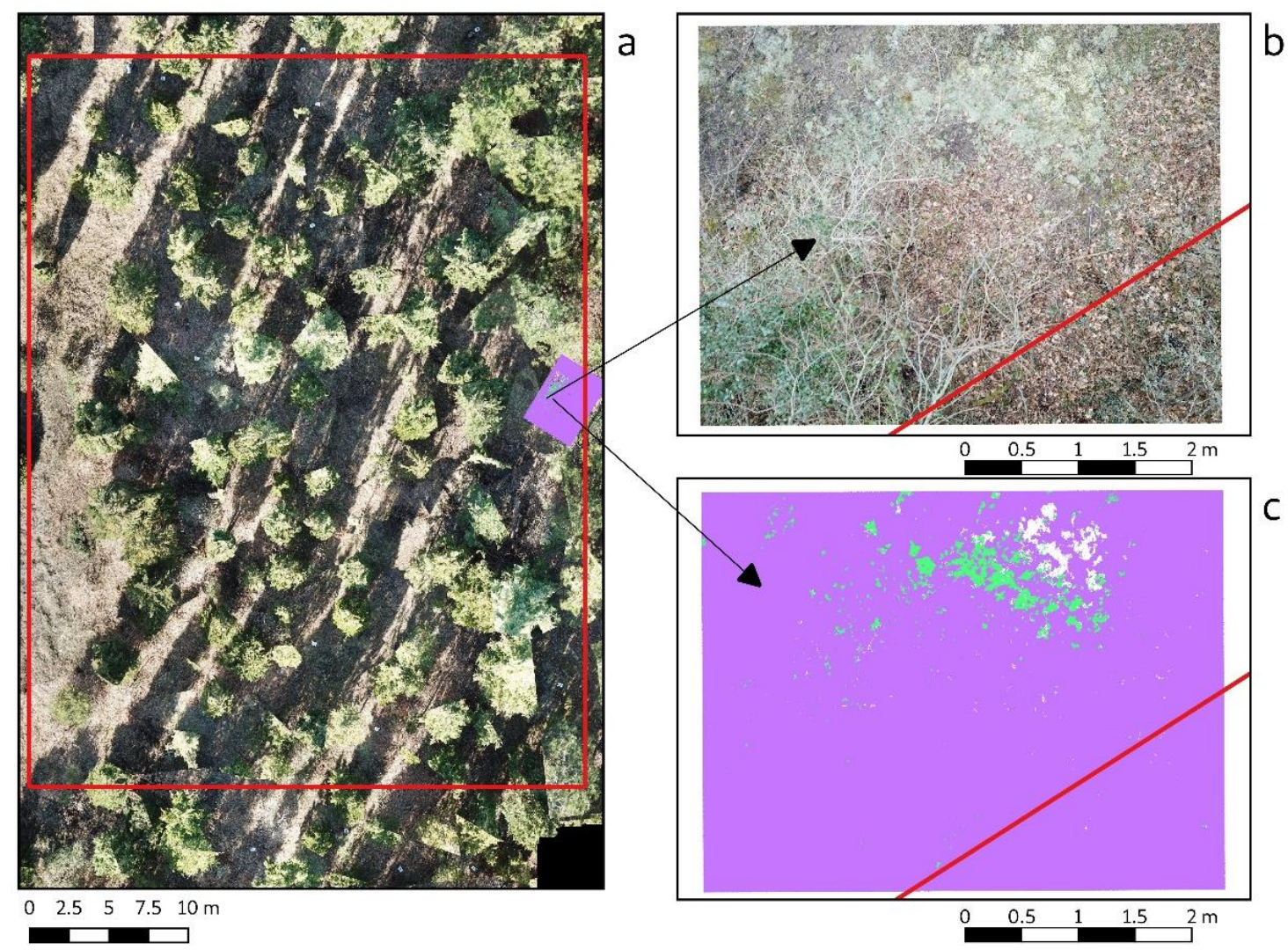

Figure 1. a) Orthophoto produced from aerial photographs taken from 12 meters height, b) aerial photographs taken from 3-5 meters height, c) classified raster map of lichen species (white pixels: $C$. foliacea, green pixels: $C$. rangiformis)

When the branching structure of the trees is analyzed, it is seen that (except few individuals) black pine and cypress do not ramify down to the breech of the trees; whereas oak and mock privet branch down to the bottom of the trees. Crown base height for black pine is $2.83 \mathrm{~m}$ and $0.97 \mathrm{~m}$ for cypress on average. 
Table 1. Summary statistics of crown projection area, height, and distance to nearest neighbor of plants in the study area

\begin{tabular}{c|c|c|c|c|c|c|c}
\hline variable & species & n & Mean & Std. Deviation & Minimum & Maximum & sum \\
\hline \multirow{2}{\text{crown}}{$\begin{array}{c}\text { projection } \\
\left(\mathbf{m}^{2}\right)\end{array}$} & mock privet & 29 & 3.55 & 2.22 & 0.97 & 9.68 & 105.66 \\
& black pine & 12 & 12.01 & 5.4 & 5.95 & 21.87 & 145.32 \\
& oaks & 44 & 4.46 & 4.24 & 0.53 & 25 & 188.5 \\
& cypress & 102 & 5.68 & 3.98 & 0.31 & 22.81 & 568.56 \\
\hline & mock privet & 29 & 1.7 & 0.69 & 0.5 & 3 & \\
height (m) & black pine & 12 & 7.58 & 0.63 & 6.5 & 8.5 & \\
& oaks & 44 & 2.42 & 1.07 & 0.5 & 5 & \\
& cypress & 102 & 7.56 & 1.73 & 1 & 12 & \\
nearest & mock privet & 29 & 3.41 & 2.17 & 0.93 & 7.84 & \\
distanbor $(\mathbf{m})$ & black pine & 12 & 4.75 & 7.02 & 2.17 & 27.01 & \\
& oaks & 44 & 2.87 & 1.21 & 1.33 & 6.74 & \\
\hline
\end{tabular}

\section{Species data}

Three species of terricolous lichens; Cladonia foliacea (Huds.) Willd. (Syn.: Cladonia convoluta (Lam.) Anders), Cladonia furcata (Huds.) Schrad. subsp. furcata and Cladonia rangiformis Hoffm. were collected from the study area in March 2019. The lichen specimens were treated with a chemical spot test and identified with a stereomicroscope (Nikon SMZ445) according to the keys of references (Hodgetts, 1992; Purvis et al., 1992; Nimis and Martellos, 2004; Eversham, 2015; AFL, 2019; British lichens, 2019; Irish lichens, 2019). Nomenclature of the species mainly follows the Index Fungorum (2019) and MycoBank Database (2019).

Thallus of $C$. foliacea is fruticose when with podetia, but mostly squamulose greenish grey, forming compact mats (Nimis and Martellos, 2004), squamules 4-10 mm x 1-3 mm (Hodgetts, 1992). Thallus of $C$. rangiformis is fruticose, greenish grey to whitish grey, shrubby, (1-3 mm long and broad), forming tuft, (Nimis and Martellos, 2004), podetia 20-60 mm tall (Hodgetts, 1992; Nimis and Martellos, 2004). Thallus of $C$. furcata subsp. furcata is fruticose, podetia 20-70 mm tall, forming irregular tufts (Hodgetts, 1992).

C. foliacea was easily noticed in the aerial photos since it has a quite bright color. It was not possible to distinguish $C$. furcata subsp. furcata which is mixed with the predominant species in the study area, $C$. rangiformis, in the aerial photos, therefore these two species were considered together, and their mention in the text as $C$. rangiformis should be considered as $C$. rangiformis $(+C$. furcata).

The crown projection of the trees and the shrubs present at the survey area were digitized using the orthophoto generated by aerial photographs taken from $12 \mathrm{~m}$ height and the centroids of crown projections were regarded as trees (or shrubs) position coordinates. Minimum enclosing circles surrounding the crown projection were produced and accepted as crown projection (Figure 2) and the radius and areas of these circles were calculated (Table 1). The plant species were identified, their height and crown base height were measured in the field. 


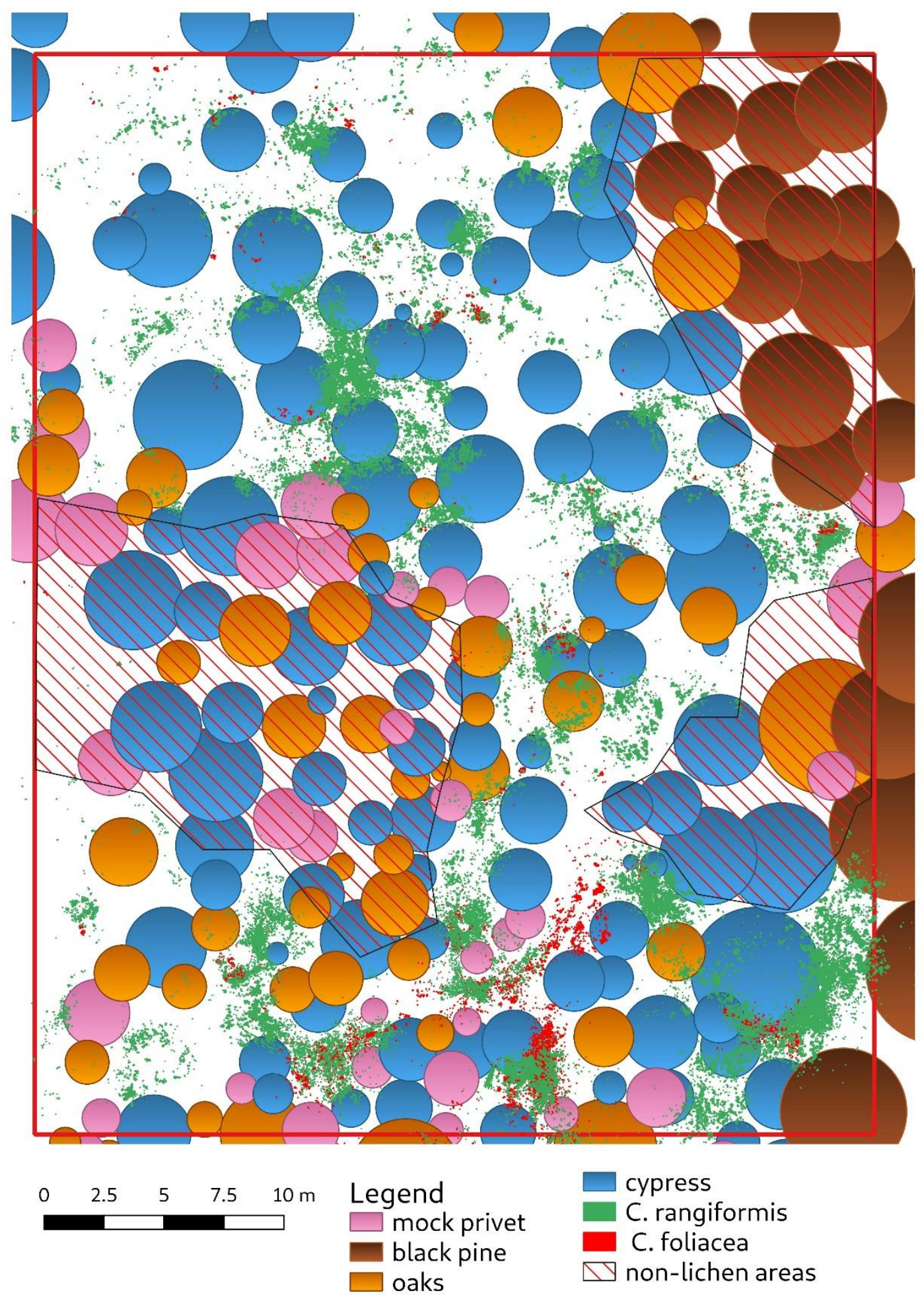

Figure 2. Distribution of trees, shrubs, and lichens in the survey area. No or very few lichens were detected in the red hatched areas 


\section{Data collection and preparation for analysis}

In regional, landscape, ecosystem and small-scale terricolous lichen studies, data were collected through sampling based surveying in the field such as transect based sampling (Pietrasiak et al., 2011; Bowker et al., 2013), random sampling (Maestre, 2003; Concostrina-Zubiri, 2018; Gutiérrez et al., 2018) or systematic sampling in the field (Ochoa-Hueso et al., 2011; Tilk et al., 2018). In our study, data regarding the lichen population in the study area was collected total count by aerial survey using one of the advanced technology's opportunities, "unmanned aerial vehicle-UAV" with the 12 megapixel resolution RGB camera in March 2019. With this goal in mind, the two-step aerial survey was conducted. First, an orthophoto of the survey area was produced using the photogrammetric method (Open Drone Map, 2019) with images captured from $12 \mathrm{~m}$ above the ground through an autonomous aerial photography covering the entire survey area (Figure 1a). It has been detected that the spatial resolution of these images (ca. $5 \mathrm{~mm}$ ) was insufficient in distinguishing lichens. Thereupon new aerial images of lichens with a higher spatial resolution $(<=2 \mathrm{~mm})$ were obtained by manual flight of an unmanned aerial vehicle between trees at a height of approximately 3-5 meters above ground.

Since sizes of lichen individuals are rather small, it is very arduous to distinguish them individually in aerial photographs. As a result, lichen patches formed by individual lichens getting together were used as the material in this study. To objectively determine the boundaries of lichen patches from images obtained from a 3-5 meters height, "Trainable Weka Segmentation" (Arganda-Carreras et al., 2017) method was used. 188 aerial photographs were classified in this method, and so objectively determined lichen patches' boundaries were saved as raster data. RGB images captured from 3-5 meters height and the classified raster data (Figure $1 b, c$ ) were transformed into geo-registered raster data through georectification with the help of the orthomosaic map of the survey area. These geo-registered raster maps were first converted to vector data and then merged to obtain the boundaries of lichen patches as vector maps. The area corresponding to each lichen patch was calculated ( $C$. rangiformis $\mathrm{n}=25025$, C. foliacea $\mathrm{n}=5598$ polygon) and these areas were used to create patch size classes (Table 2). In order to use the lichen patches in analysis, their polygon centroids were obtained. In order to investigate the relationships between the lichen patches and trees, lichen patch centroids were clustered.

Table 2. Total area and number of lichen patches

\begin{tabular}{c|c|c}
\hline size class / species & Cladonia rangiformis $\left(\mathbf{c m}^{\mathbf{2}}\right)$ & Cladonia foliacea $\left(\mathbf{c m}^{2}\right)$ \\
\hline VSLP & $6.48(\mathrm{n}=18003)$ & $2.09(\mathrm{n}=4226)$ \\
SLP & $46834.83(\mathrm{n}=4900)$ & $9671.67(\mathrm{n}=1011)$ \\
MLP & $38617.97(\mathrm{n}=1258)$ & $6823.80(\mathrm{n}=230)$ \\
LLP & $53010.72(\mathrm{n}=636)$ & $8759.78(\mathrm{n}=101)$ \\
DLP & $123216.02(\mathrm{n}=228)$ & $24916.91(\mathrm{n}=30)$ \\
\hline Totals of size classes & $261679.54(\mathrm{n}=25025)$ & $50172.16(\mathrm{n}=5598)$ \\
\hline Totals & \multicolumn{2}{|c}{$311851.70(\mathrm{n}=30623)$} \\
\hline
\end{tabular}

Lichen patch centroids were clustered using density-based spatial clustering of applications with noise (DBSCAN) algorithm (Ester et al., 1996). In this process, lichen 
patch clusters (hereafter LPC) were generated with a minimum of 5 neighbors in each cluster and a maximum distance of 0.25 meters between LPCs.

Trees and shrubs at a distance below 4 meters to the centers of LPCs were selected. The distances and azimuth values between the center of LPCs and the position of trees and shrubs were calculated (Figure 3).
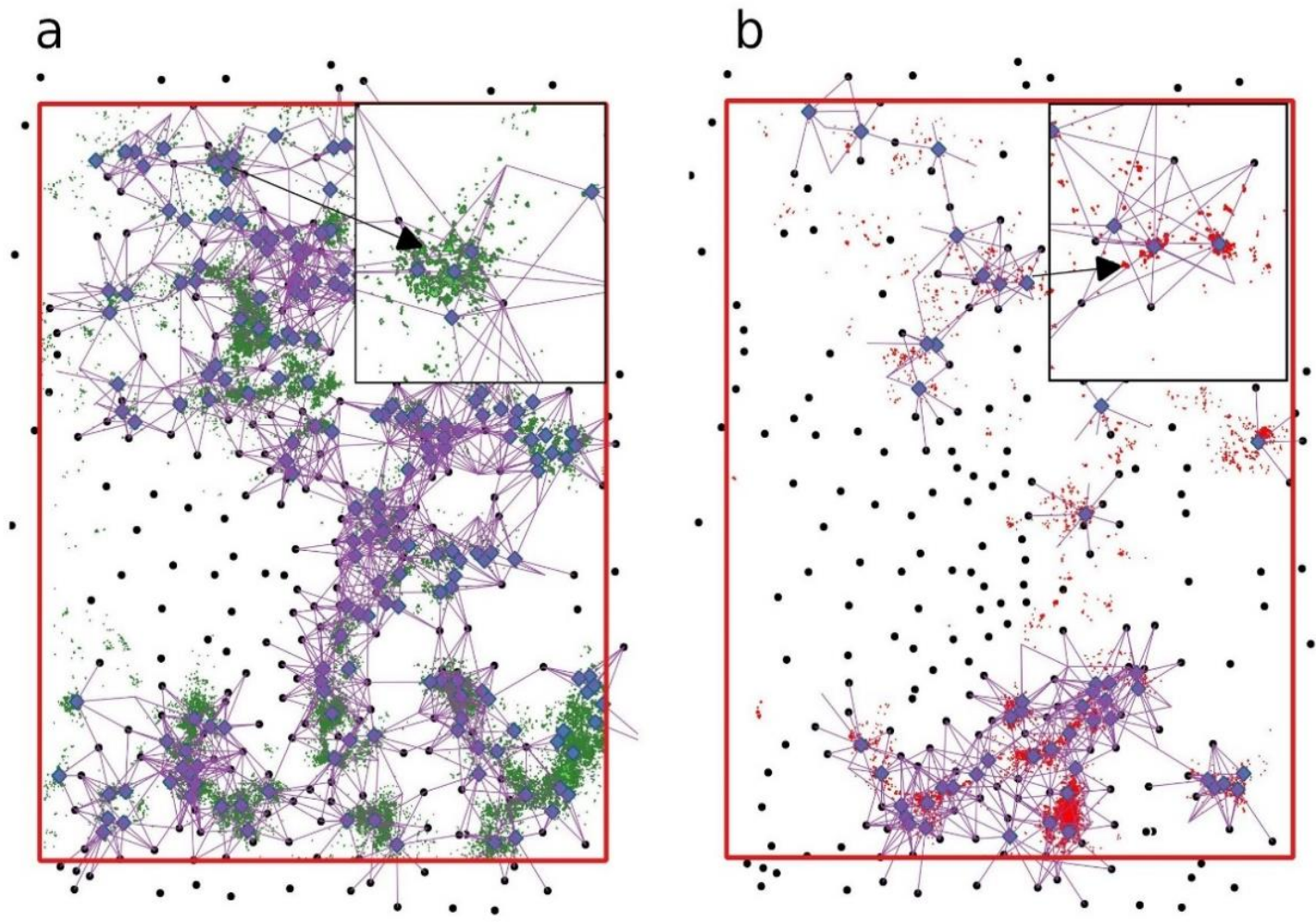

Figure 3. Hublines for the calculation of azimuth and distance between centers of LPC and position of trees and shrubs; a) C. rangiformis b) C. foliacea

\section{Statistical Analysis}

Since the studied objects were represented areally as lichen patches and the aerial survey was conducted over the entire area, analyses were conducted using a two-tiered approach: a cluster of lichen patches and whole lichen patches. In order to fulfill this objective, the relationships between LPC centers and surrounding trees and shrubs were investigated with circular statistics methods. Whether whole lichen patches fit the power-law distribution was tested and their distribution was inspected using spatial point pattern analyses.

In order to be able to evaluate differences between lichen patches based on their sizes, both lichen patches were sorted into 4 size classes as: Small lichen Patch (SLP) $\left(5-20 \mathrm{~cm}^{2}\right)$, Middle Lichen Patch (MLP) $\left(20-50 \mathrm{~cm}^{2}\right)$, Large Lichen Patch (LLP) $\left(50-150 \mathrm{~cm}^{2}\right)$, Dead Lichen Patch (DLP) $\left(>150 \mathrm{~cm}^{2}\right)$. Patches covering areas less than $5 \mathrm{~cm}^{2}$ (Very Small Lichen Patch) were not used in analyses in order to minimize classification and geometrical accuracy errors.

For analyses regarding the distribution of LPC centers around trees (or shrubs), the circular package (Agostinelli and Lund, 2017) of the R software was employed (R Core 
Team, 2018). To test whether whole community lichen patches fit power-law distribution (Kefi, 2007; Bowker et al., 2013, 2014) the "poweRlaw" package of the R software (Gillespie, 2015) was used. For the spatial point pattern analysis, firstly whether the lichen distribution is homogeneous was tested with quadrattest (Wang et al., 2010) and it was determined that the distribution is not homogeneous. Therefore the mentioned analyses were conducted inhomogeneously over the entire area (the word inhomogenous is synonymous with the word heterogeneous, but since the word inhomogeneous is used in spatstat package, this word was preferred in our study). The univariate pair correlation function $\mathrm{g}(\mathrm{r})$ was employed in order to determine the spatial pattern of the $C$. rangiformis and C. foliacea, (Stoyan and Stoyan, 1994; Wiegand and Moloney, 2014) under a inhomogeneous Poisson null model. To detect spatial relationships between lichen pathes in different size classes, and between lichen pathes and trees/shrubs, the bivariate pair correlation functioning $g_{12}(r)$ was used. For spatial point pattern analyses, the "spatstat" package (Baddeley et al., 2015) of the R software was used.

In the followed methodological approach (Figure 4) all spatial analyses were performed with Quantum GIS (Quantum GIS Development Team, 2019) and "weka trainable segmentation" FIJI (Schindelin et al., 2012), and all statistical analyses were performed using R (R Core Team, 2018) software.

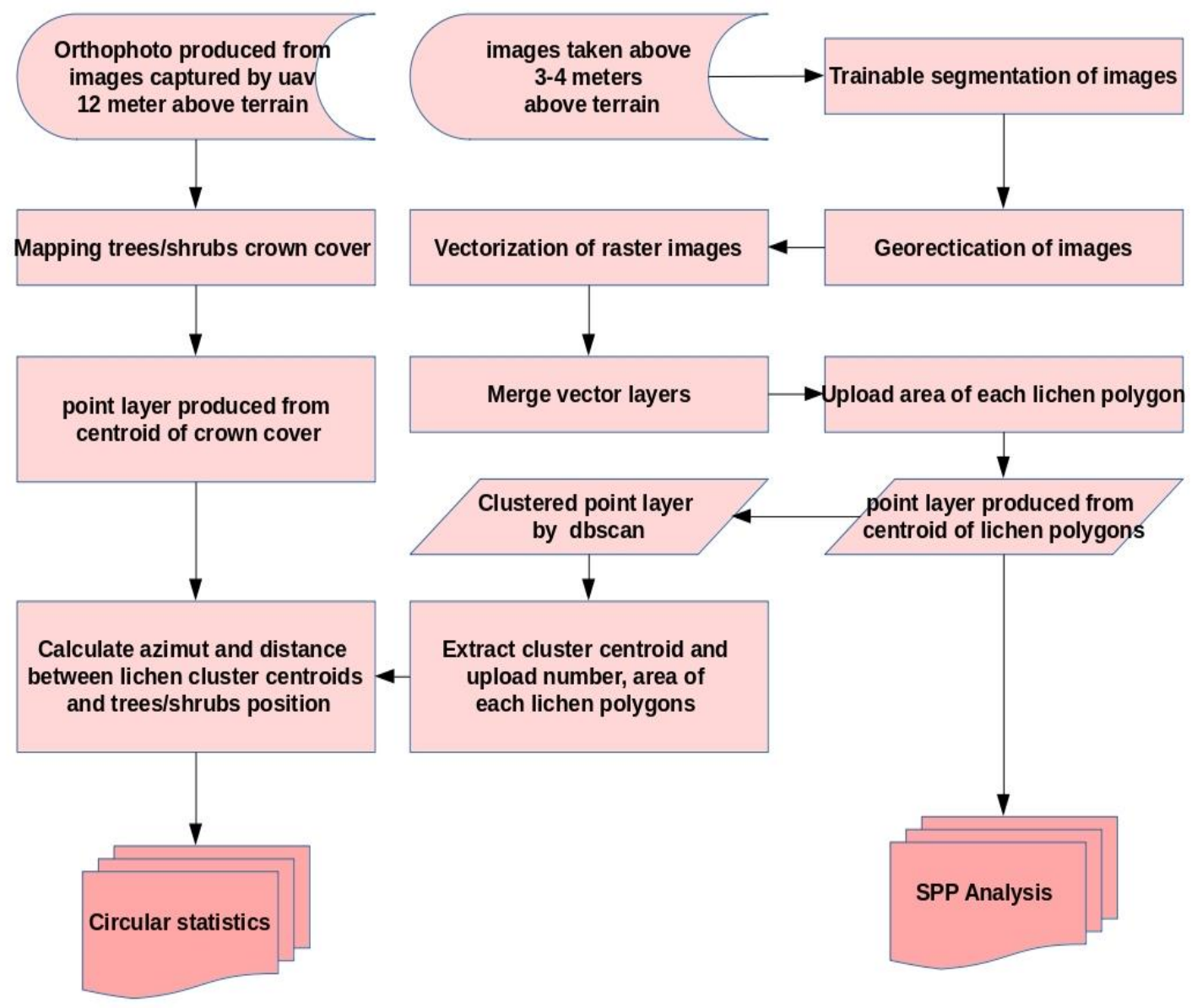

Figure 4. Workflow of the methodological approach followed in the study 


\section{Results}

\section{Cover area of trees (or shrubs) and lichens}

In the study area, the crown projection area of black pine, cypress, oak, and mock privets were calculated to be $145.32 \mathrm{~m}^{2}, 568.56 \mathrm{~m}^{2}, 188.50 \mathrm{~m}^{2}$, and $105.66 \mathrm{~m}^{2}$, respectively and the gap area was calculated to be $684.55 \mathrm{~m}^{2}$. Since the crown projections were intertwined, the total coverage area resulted to be $184 \mathrm{~m}^{2}$ more than the exact area of the study area.

The total area covered by the $C$. rangiformis $(+C$. furcata) in the study area was 5 times higher than that of the $C$. foliacea (Table 2). The total area covered by the lichen species is $31.19 \mathrm{~m}^{2}$ which lies over $2 \%$ of the area. When the total area covered by lichen species were analyzed according to their size classes, 25025 lichen patches in C. rangiformis, 5598 lichen patches in C. foliacea, and 30623 lichen patches in total were determined (Table 2). For both lichen species, the highest lichen patch number was seen in VSLP; however, this size class' total cover is very low (Table 2). Among the size classes, DLP was the one with the highest total area, and it was measured 5 times higher for $C$. rangiformis than that for C. foliacea on average (Table 2).

\section{Cluster of lichen patches analysis}

\section{Directional distribution of LPC centers around trees (or shrubs)}

For the directional analyses of the lichen patch clusters, SLP, MLP, LLP, and DLP were utilized. In consequence of the conducted clustering process 199 clusters for C. rangiformis (Figure 3a), and 49 clusters for $C$. foliacea (Figure $3 b$ ) were determined. The average size of $C$. rangiformis patches was $37.27 \mathrm{~cm}^{2}$, and the average size of C. foliacea patches was $36.57 \mathrm{~cm}^{2}$. The average distance of lichen patches to cluster centers was $0.74 \mathrm{~m}$ for $C$. rangiformis, whereas it was $0.41 \mathrm{~m}$ for $C$. foliacea.

When the mean directions of trees and stumps closer than $4 \mathrm{~m}$ to LPC centers are considered, $C$. rangiformis LPC centers are located at the north of mock privet, east of oaks, and northeast of stumps (Figure 5). C. rangiformis LPC centers are located at the north of cypresses until $2.5 \mathrm{~m}$ distance, whereas at around 3-3.5 m they are at the northwest (Figure 5). Even though $C$. foliacea interaction with trees and shrubs is more erratic, its LPC's are located approximately towards the north of cypress and oak (Figure 5).

The amount of trees around $C$. rangiformis LPC centers are higher than those around C. foliacea LPC centers (Figure 5). The number of trees sorted from high to low at all distances from $C$. raniformis LPC centers are; cypress, stumps, oak, and mock privet (Figure 5). Also, while until $2 \mathrm{~m}$ stump and cypress individuals amounts are close, after $2 \mathrm{~m}$, cypress amount is ahead (Figure 5). For $C$. foliacea cluster centers, the same ranking is: cypress, mock privet, stumps, and oak (Figure 5).

\section{Whole lichen patches analysis}

\section{Power-law distribution analysis of lichen patches}

The fact that lichen patch sizes differ between $0.5 \mathrm{~mm}^{2}$ and $2.20 \mathrm{~m}^{2}$ encouraged testing the aptitude of power-law distribution. According to the results of the hypothesis test, the logarithmic values of the number of $C$. rangiformis ( $p$-value $=0.38$ ) and $C$. foliacea $(p$-value $=0.44)$, and their patch-sizes fit power-law distribution (Figure 6). It was observed that while the more abundant ones with small lichen patch-sizes fit the 
power-law distribution better, the ones with big patch-size are relatively further from power-law distribution (Figure 6).

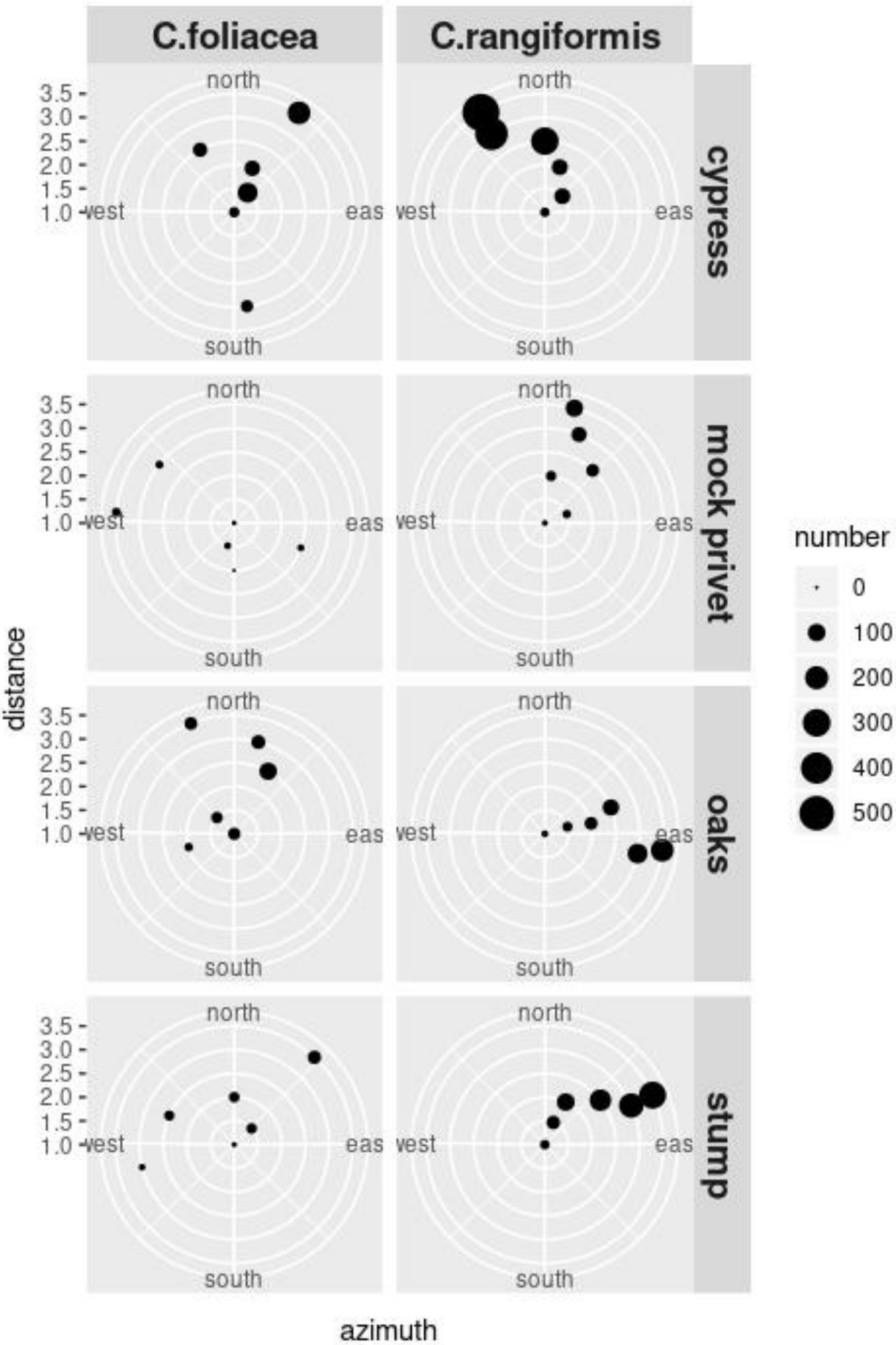

Figure 5. Directional interaction based on distance and mean azimuth between the cluster of lichen patches and trees and shrubs. White circles show the distance from LPC centers, blackfilled circles show plant cumulative count 

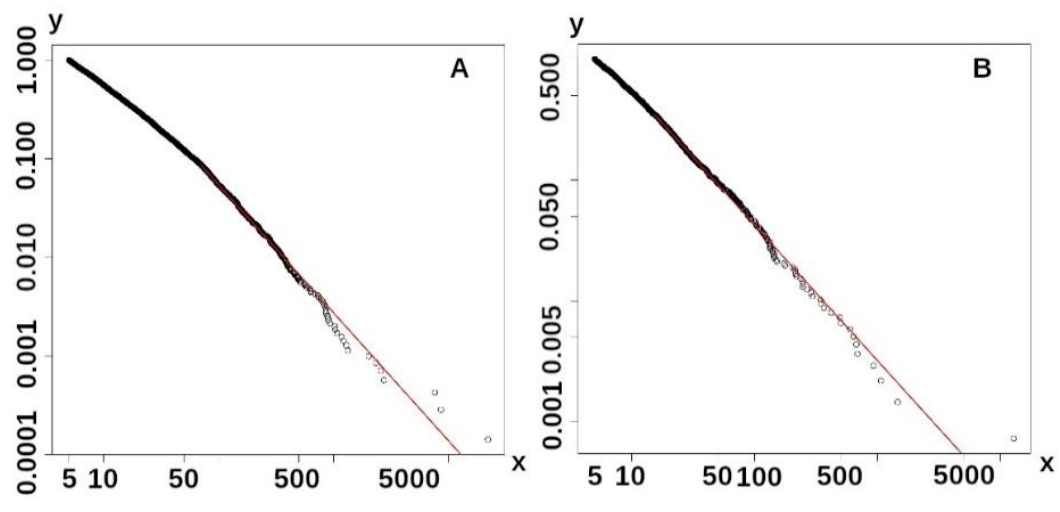

Figure 6. Cumulative distributions of lichen patches for a) C. rangiformis, b) C. foliacea, shown with logarithmic scales

\section{Univariate point patterns analysis of lichens patches}

According to the results of univariate point pattern analyses, C. rangiformis and C. foliacea show significant clustering in short distance (Figure $7 a, b)$. g(r) values of $C$. foliacea resulted to be higher than the values of $C$. rangiformis. Clustering distance was observed to be same for C. rangiformis $(\mathrm{r}<2.5 \mathrm{~m})$ as $C$. foliacea $(\mathrm{r}<2.5 \mathrm{~m})$ (Figure 7$)$. When the two species are together, similar clustering was observed in short distance $(\mathrm{r}<2.5 \mathrm{~m})$ (Figure $7 c)$. Besides this, both species demonstrate significant regular distribution after short distance clustering $(r>2.5 \mathrm{~m})$.

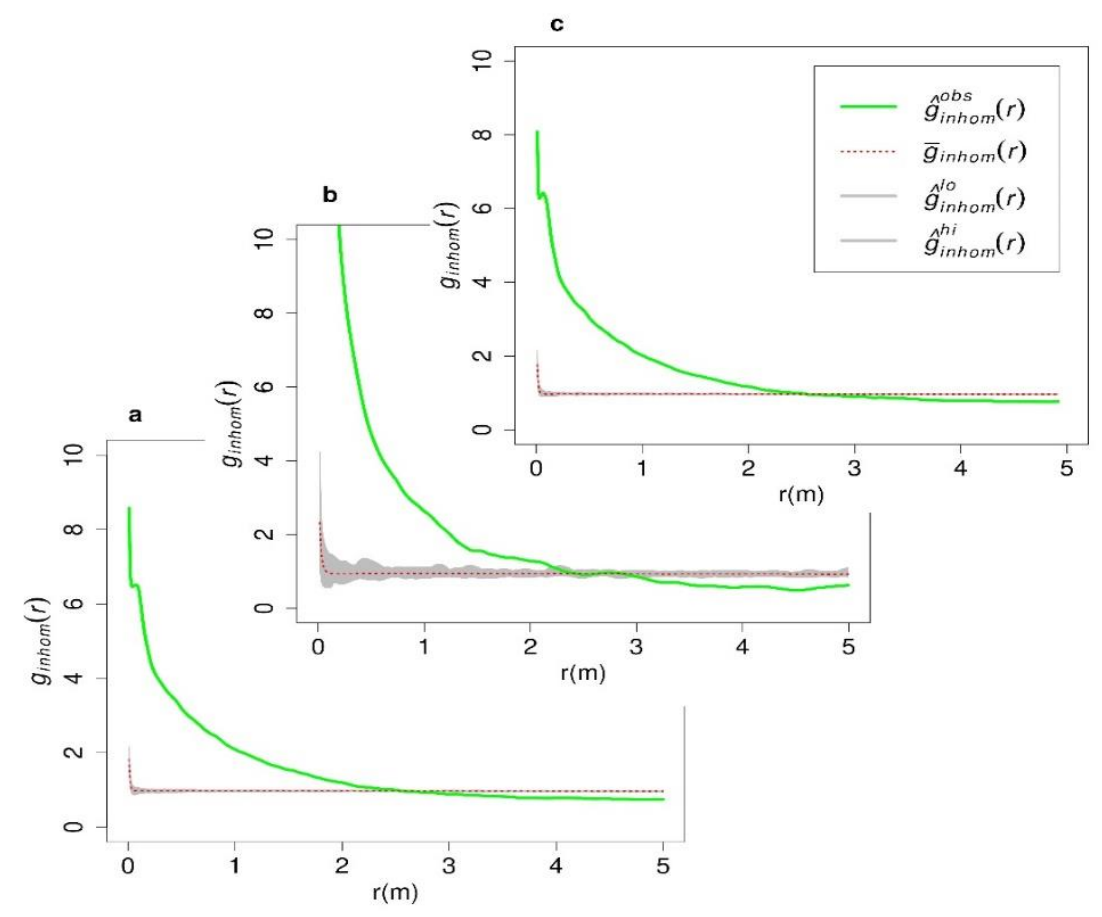

Figure 7. Univariate point patterns analyses of a) C. rangiformis b) C. foliacea c) whole lichen patches using inhomogeneous pair-correlation function. $g_{\text {inhom }}(r)=$ green line; gray areas indicate boundaries of the simulation envelope constructed from 99 simulations of an inhomogeneous Poisson process with inhomogeneity given by kernel smoothed intensity function from a point pattern 
The patterns created by all size classes of the species, both separately and together, univariate point pattern analyses done according to size classes gave similar results (Figure 8). According to the results of univariate analyses conducted considering size classes, random distribution was observed after 1-1.5 meters for $C$. foliacea at LLP and DLP, and after 5 and 6 meters at DLP for C. rangiformis (Figure 8).
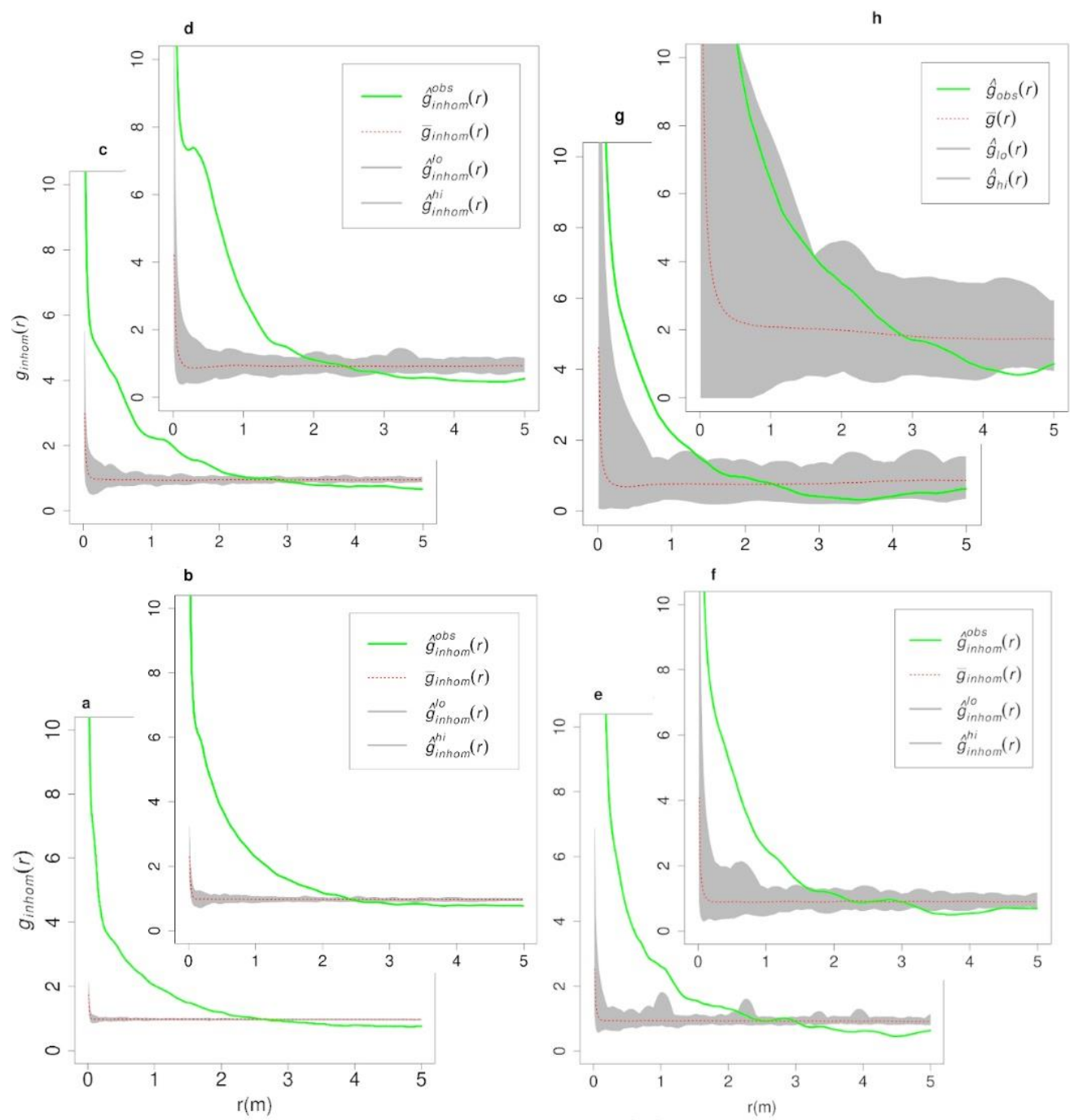

Figure 8. Univariate point patterns analyses of C. rangiformis based on size class; a) SLP, b) $M L P, c) L L P, d) D L P$ and Univariate point patterns analyses of $C$. foliacea based on size class e) $S L P, f) M L P, g) L L P, h) D L P$ using inhomogeneous pair-correlation function. $g_{\text {inhom }}(r)=$ green line; gray areas indicate boundaries of the simulation envelope constructed from 99 simulations of an inhomogeneous Poisson process with inhomogeneity given by kernel smoothed intensity function from a point pattern

Bivariate point pattern analysis of lichen patches size classes

SLP of $C$. rangiformis is attracted by other size classes of lichen patches in short distance $(\mathrm{r}<2 \mathrm{~m})$; however, after this distance $(\mathrm{r}>2 \mathrm{~m})$, repulsion is observed (Figure 9). A similar situation exists between MLP and LLP, between MLP and DLP, and between LLP and DLP (Figure 9). 

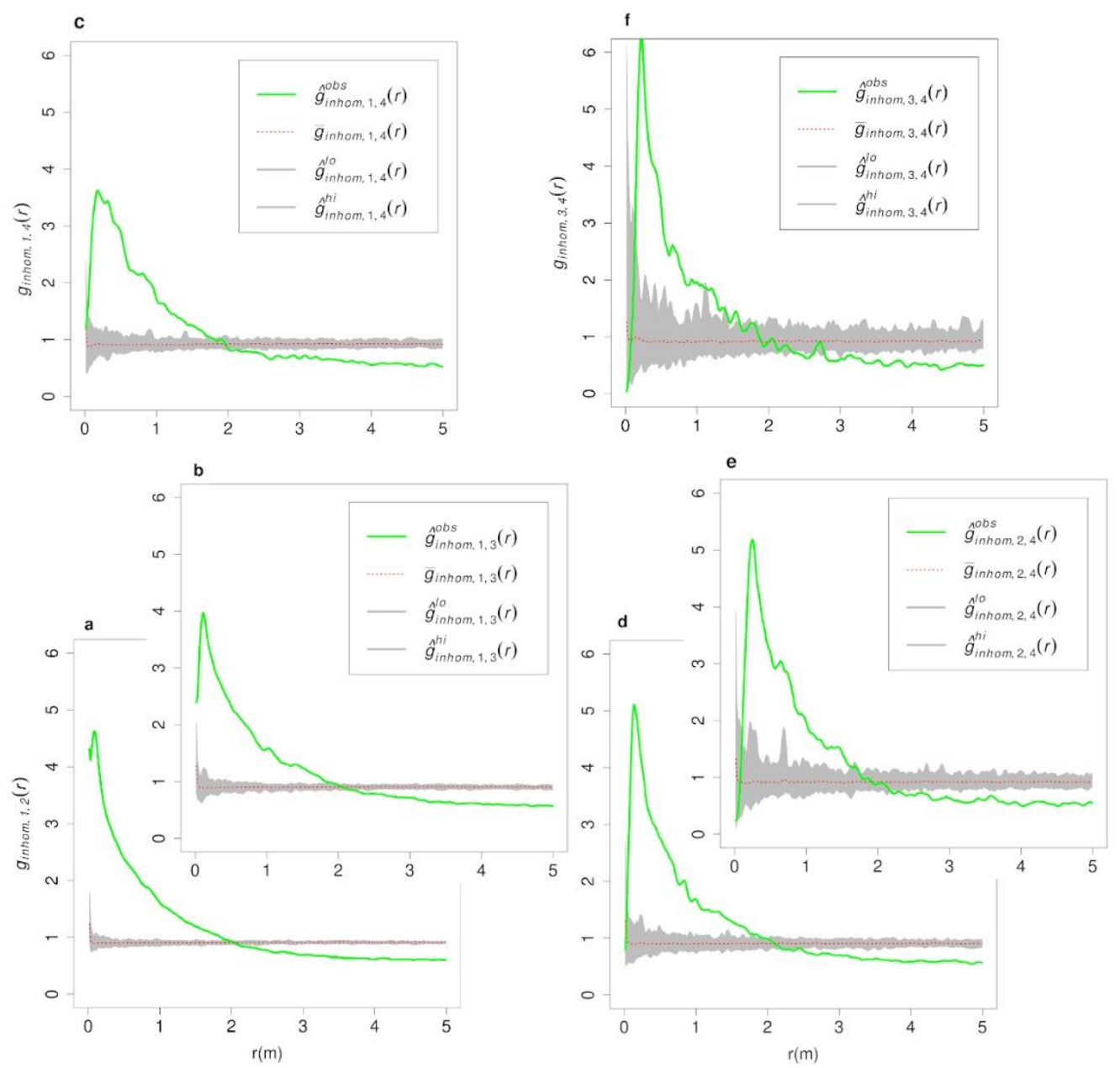

Figure 9. Bivariate point pattern analysis of $C$. rangiformis based on a) $S L P$ to $M L P, b) S L P$ to $L L P, c) S L P$ to DLP, d) MLP to LLP, e) MLP to DLP, f)LLP to DLP using inhomogeneous cross-type pair-correlation function $g_{\text {inhom }}(r)=$ green line; gray areas indicate boundaries of the simulation envelope constructed from 99 simulations of an inhomogeneous Poisson process with inhomogeneity given by kernel smoothed intensity function from a point pattern

SLP of $C$. foliacea species is attracted by MLP and LLP in short distance $(\mathrm{r}<2 \mathrm{~m})$, but after this distance $(\mathrm{r}>2 \mathrm{~m})$, repulsion is observed. MLP is again attracted by LLP at short distance $(\mathrm{r}<2 \mathrm{~m})$ (Figure 10). Other bivariate analyses were conducted, but since the DLP had $n=30$ and as a consequence the resulting envelopes were highly irregular, it was not evaluated.

Between $C$. rangiformis and $C$. foliacea, attraction is observed in short distance $(\mathrm{r}<1.5 \mathrm{~m})$, however after this distance, repulsion is observed (Figure 11).

\section{Bivariate point pattern analysis of lichen patches and trees/shrubs}

It was determined that both lichen species are repulsed by the cypress (Figure 12). Other bivariate analyses were performed, but since $n$ values were very low and therefore the resulting envelopes were irregular they were not evaluated. 


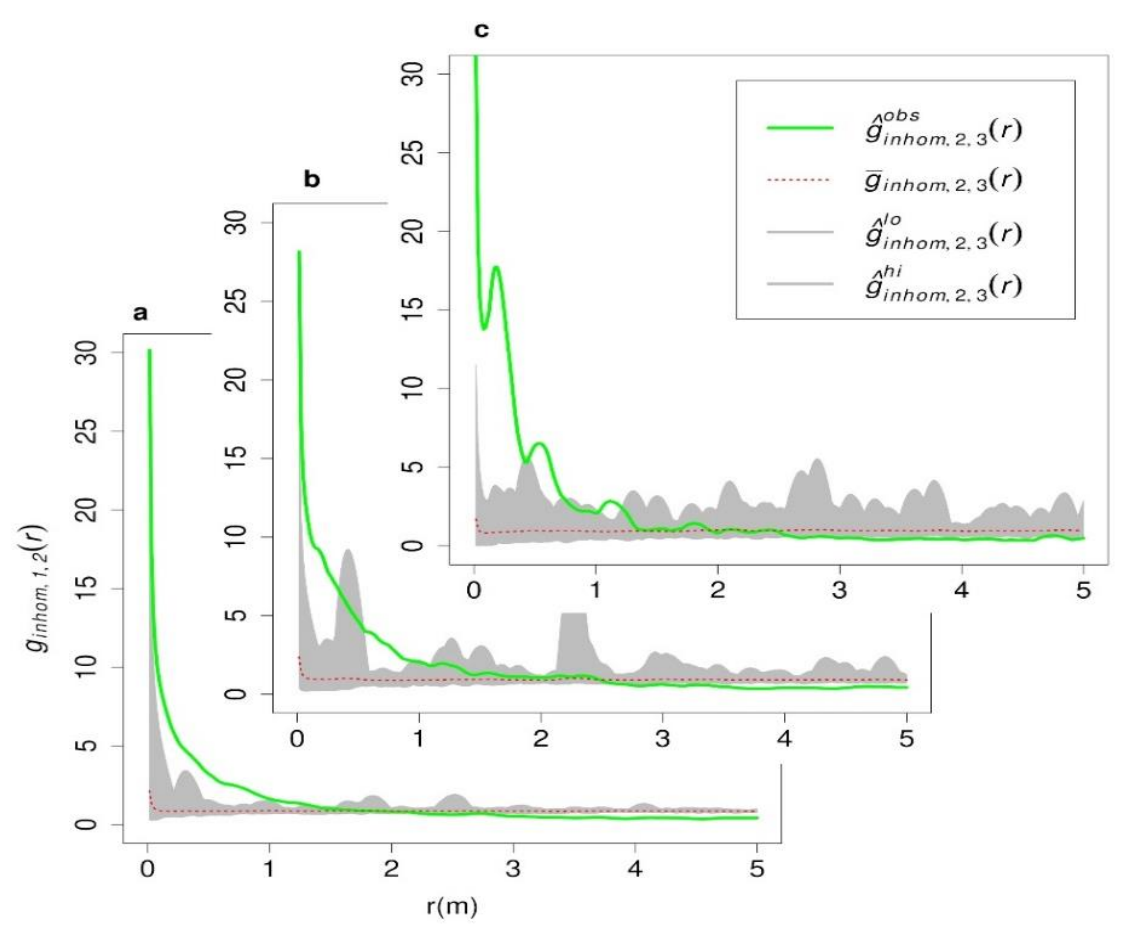

Figure 10. Bivariate point pattern analysis of C. folicaea based on a) SLP to MLP, b) SLP to $L L P, c) S L P$ to DLP using inhomogeneous cross-type pair-correlation function. $g_{\text {inhom }}(r)=$ green line; gray areas indicate boundaries of the simulation envelope constructed from 99 simulations of an inhomogeneous Poisson process with inhomogeneity given by kernel smoothed intensity function from a point pattern

a

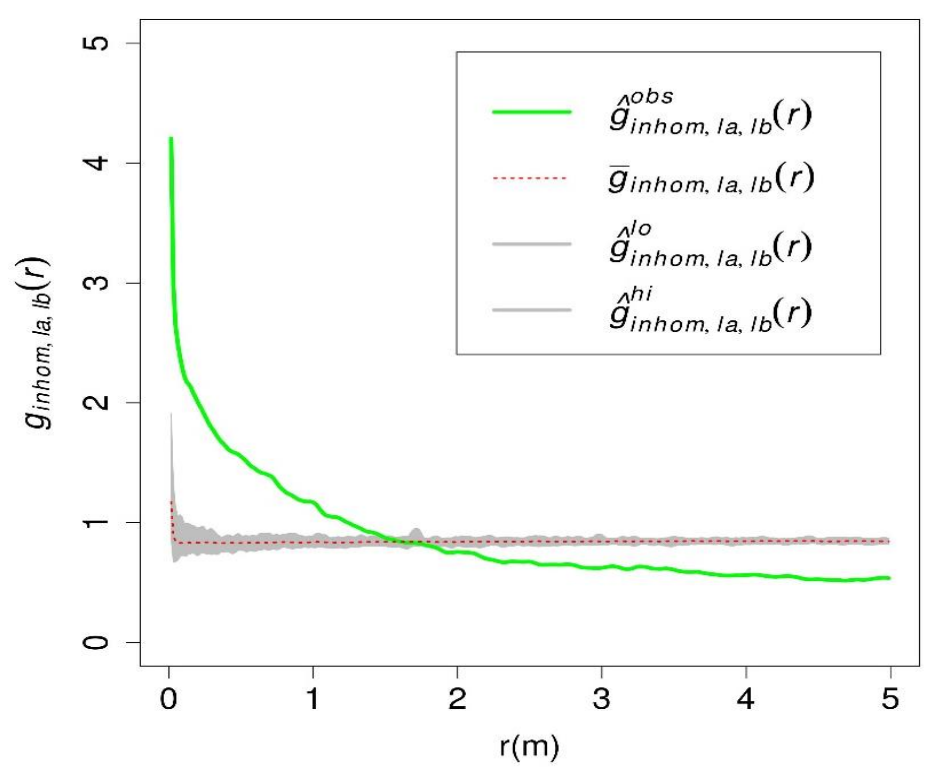

Figure 11. Bivariate point pattern analysis of C. folicaea and C. rangiformis based on whole patches using inhomogeneous cross-type pair-correlation function. $g_{\text {inhom }}(r)=$ green line; gray areas indicate boundaries of the simulation envelope constructed from 99 simulations of an inhomogeneous Poisson process with inhomogeneity given by kernel smoothed intensity function from a point pattern 
a

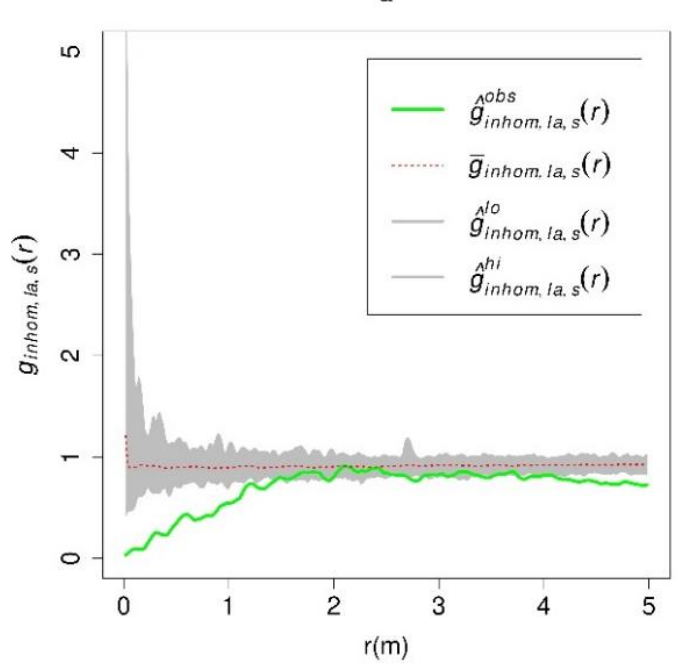

b

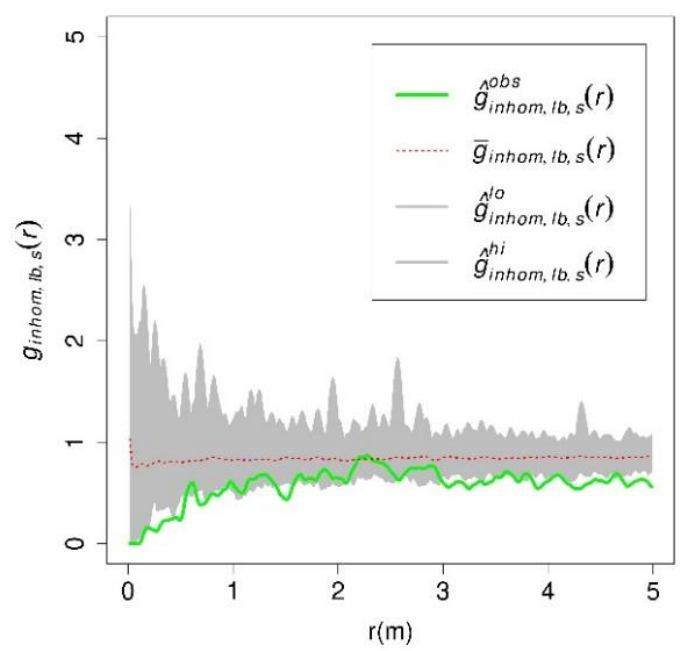

Figure 12. Bivariate point pattern analysis between cypress and a) C. rangiformis, $b) C$. folicaea using inhomogeneous cross-type pair-correlation function $g_{\text {inhom }}(r)=$ green line; gray areas indicate boundaries of the simulation envelope constructed from 99 simulations of an inhomogeneous Poisson process with inhomogeneity given by kernel smoothed intensity function from a point pattern

\section{Discussion}

Factors affecting the distribution of the important genus of terricolous lichens Cladonia have been studied for a long time (Yarranton, 1975). Cladonia generally can grow on soil, but can also be found in other substrates such as bark, rotting wood, dune system and among moss (Bowker et al., 2006; Osyczka, 2006; Gheza et al., 2016; Tilk et al., 2018; Sevgi et al., 2019). We contributed by investigating the spatial distribution of the species $C$. foliacea and $C$. rangiformis $(+C$. furcata) and their interactions with tree/shrub species. The complicated relationships based on direction and distance between the studied objects were investigated with an aerial survey. These relationships can also be investigated with different re/sampling methods and/or new studies could be done, because the area of such size $\left(1575 \mathrm{~m}^{2}\right)$ captured aerially is 17500 times the size of the $30 \mathrm{~cm} \times 30 \mathrm{~cm}\left(0.09 \mathrm{~m}^{2}\right)$ sample areas which are widely used in lichen studies. Hence just as different research can be done by resampling this permanent research area, temporal monitoring studies can also be conducted.

In afforestation areas in the Mediterranean region, new species brought into the area through planting and the presence of dominated natural species in the environment affects the distribution of terricolous lichens (Loppi et al., 2004; Concostrina-Zubiri et al., 2018). Similarly, in our study species brought into the area and natural species affected the distribution of terricolous lichens in small-scale. In the spatial clustering of two terricolous lichen species, 199 clusters for C. rangiformis (Figure 3), and 49 clusters for $C$. foliacea were found. Based on these results, $C$. rangiformis has a higher number of the lichen patches that has joined in size classes and their spatial distribution in small-scale is high. Another evidence that shows this effect more clearly is the mean direction of LPC centers with respect to trees (Figure 5). LPC centers are inclined to be on specific sides of tree species even at various distances (Figure 5). This inclination is more apparent for the $C$. rangiformis. Both species' cluster centers interacted 'by distance' most with 
cypress, then with other species (Figure 5). Oaks and mock privet being fewer in number and them gathering together at specific parts of the area may have made cypress' effects on lichens more obvious compared to other species. Results obtained for the C. rangiformis supports previous studies (Loppi et al., 2004).

When the distance from LPC centers at which trees were located was investigated, it has been found that lichen species were found under the crown projection area of cypress; however, no such result has been found for mock privet and oak. While the branching until bottom of oak and mock privet individuals block lights from passing through, the fact that branching begins at $97 \mathrm{~cm}$ on average and the branching angle is greater may have allowed more light to pass through the crown. As a result, while lichens with low shade tolerance were not able to disperse beneath the canopy of mock privet and oak, they were able to disperse beneath the canopy of some cypress individuals (Eldridge, 1999). These results are in line with studies which have revealed the negative effects of oak on Cladonia species' distribution (Ochoa-Hueso et al., 2011; Goldberg and Heine, 2014). Distribution of Cladonia species in open microsites is affected by trees (Crittenden, 1999). Another factor which augments this effect is forest litter (Eldridge, 1999). Although in our study forest litter-related evaluations were not conducted, the dense amounts of forest litter often produced by oak may have contributed in hindering lichens to enter beneath the crown projection area. In our study, besides this effect of oak, it has been determined that there are nearly no lichens in the region where oak is present with mock privet (non-lichen area in the left of Figure 2).

Power-law distribution is being utilized successfully in vegetation studies (Kefi et al., 2007) and explains the relationship between epiphytic lichen species diversity and tree diameter (Buckley, 2011). Bowker et al. (2013, 2014) stated that analysis of the patchsize distributions of biological biosoil crusts including terricolous lichens fit power-law distribution. Our study validated that terricolous lichen species' patch sizes directly demonstrate power-law distribution, which is in line with our expectations.

It is thought that the inhomogeneity of lichen distribution arises from the distribution of the trees and shrubs in the area, which proves our hypothesis to be true. It is considered that the intensity and distribution of pine, oak, and mock privet species in the area causes this. It is possible to perform the point pattern analysis of an irregular area by excluding these regions; however, in that case, the reasons behind in-homogeneous distribution and the actual distribution patterns of the lichens would not have been revealed, therefore this method was not preferred.

Considering all lichen size classes together, the occurrence of clustering at short distance (2-2.5 meters) and regular distribution beyond this distance is thought to be related to both the distance among trees in the afforestation area (the average distance of all trees; $1.91 \mathrm{~m}$, the average distance among cypress; $2.44 \mathrm{~m}$ ) and the fact that lichens form large colonies in the gaps of forest/shrublands by colonization. The highness of the $\mathrm{g}(\mathrm{r})$ value of $C$. foliacea results from its clustering in only specific regions of the area. Both Cladonia species demonstrating clustering and not distributing randomly goes along with Maestre's (2003) results. However, the random distribution of $C$. foliacea and C. rangiformis' large size classes, discovered through the univariate analyses conducted based on size classes, may indicate that they initially disperse randomly in the region. The existence of a positive or negative correlation between lichen patch size classes were investigated using bivariate analyses. According to the results, small size classes in both lichen species show a positive correlation with large size classes at short distance $(r<2 \mathrm{~m})$; 
however, after this distance ( $r>2 \mathrm{~m}$ ) a negative correlation was observed. This may be due to the effects of colonization, competition for space and nutrition.

The relationship between $C$. rangiformis and $C$. foliacea which is positive at short distance $(\mathrm{r}<0.5 \mathrm{~m})$, is negative after this distance. The investigation of the bivariate relationship between lichens and trees revealed significant repulsion from cypress trees.

\section{Conclusions}

This study has shown that aerial photography can be used for determining the spatial distribution of terricolous lichen species. Captured photographs will allow for comparison with photos taken at a later time period, which will in turn contribute to understanding the spatial distribution of terricolous lichen species over long periods of time. Futher studies should take into consideraiton of spatial modelling of environmental factors (i.e., tree height, crown width, shade, microtopography, soil properties) affecting the spatial distribution of lichens. Also, the effect of herbaceous plants between trees on the spatial distribution of terricolous lichens should be made clear.

Acknowledgements. The authors report that they have no conflicts of interests. We would like to thank to İstanbul Regional Directorate of Forestry and İstanbul Forest Service. Our special thanks are due to Dr. Hatice Y1lmaz for her contribution to field studies. The authors are grateful to Lale Yilmaz for the language editing of this paper.

\section{REFERENCES}

[1] Adamo, P., Vingiani, S., Violante, P. (2002): Lichen-rock interactions and bioformation of minerals. - Developments in Soil Science 28(2): 377-391.

[2] AFL (2019): Association Française de Lichénologie. - Retrieved from https://www.aflichenologie.fr/Photos_AFL/Photos_AFL_C.htm (10.07.2019).

[3] Agostinelli, C., Lund, U. (2017): R package 'circular': Circular Statistics (version 0.4-93). - URL Retrieved from https://r-forge.r-project.org/projects/circular/.

[4] Akpinar, A. U., Ozturk, S., Sinirtas, M. (2009): Effects of some terricolous lichens [Cladonia rangiformis Hoffm., Peltigera neckerii Hepp ex Müll. Arg., Peltigera rufescens (Weiss) Humb.] on soil bacteria in natural conditions. - Plant Soil and Environment 55(4): 154-158.

[5] Aptroot, A., James, P. W. (2002): Monitoring Lichens On Monuments. - In: Nimis, P. L., Schedegger, C., Wolseley, P. A. (eds.) Monitoring with Lichens- Monitoring Lichens., Kluwer Academic Publishers, Netherlands.

[6] Arganda-Carreras, I., Kaynig, V., Rueden, C., Eliceiri, K. W., Schindelin, J., Cardona, A., Sebastian Seung, H. (2017): Trainable Weka Segmentation: a machine learning tool for microscopy pixel classification. - Bioinformatics 33(15): 2424-2426. PMID28369169, doi:10.1093/bioinformatics/btx180 (on Google Scholar).

[7] Asta, J., Orry, F., Toutain, F., Souchier, B., Villemin, G. (2001): Micromorphological and ultrastructural investigations of the lichen-Soil interface. - Soil Biology and Biochemistry 33(3): 323-337.

[8] Baddeley, A., Rubak, E., Turner, R. (2015): Spatial point patterns: Methodology and applications with R. - London, UK: Chapman and Hall/CRC Press. Retrieved from http://www.crcpress.com/Spatial-Point-Patterns-Methodology-and-Applications-withR/Baddeley-Rubak-Turner/9781482210200/. 
[9] Bowker, M. A., Belnap, J., Miller, M. E. (2006): Spatial modeling of biological soil crusts to support rangeland assessment and monitoring. - Rangeland Ecology and Management 59(5): 519-529.

[10] Bowker, M. A., Maestre, F. T., Mau, L. R. (2013): Diversity and patch-size distributions of biological soil crusts regulate dryland ecosystem multifunctionality. - Ecosystems 16: 923-933.

[11] Bowker, M. A., Maestre, F. T., Eldridge, D., Belnap, J., Castillo-Monroy, A., Escolar, C., Soliveres, S. (2014): Biological soil crusts (biocrusts) as a model system in community, landscape and ecosystem ecology. - Biodiversity and Conservation 23: 1619-1637.

[12] British lichens (2019): Retrieved from http://www.lichens.lastdragon.org (10.07.2019).

[13] Buckley, H. L. (2011): Isolation affects tree-scale epiphytic lichen community structure on New Zealand mountain beech trees. - Journal of Vegetation Science 22: 1062-1071.

[14] Chen, J., Blume, H. P., Beyer, L. (2000): Weathering of rocks induced by lichen colonization- a review. - Catena 39: 121-146.

[15] Chen, J., Zhang, M. Y., Wang, L., Shimazaki, H., Tamura, M. (2005): A new index for mapping lichen-dominated biological soil crusts in desert areas. - Remote Sensing of Environment 96: 165-175.

[16] Concostrina-Zubiri, L., Martínez, I., Rabasa, S. G., Escudero, A. (2014): The influence of environmental factors on biological soil crust: from a community perspective to a species level approach. - Journal of Vegetation Science 25: 503-513.

[17] Concostrina-Zubiri, L., Martínez, I., Escudero, A. (2018): Lichen-biocrust diversity in a fragmented dryland: Fine scale factors are better predictors than landscape structure. Science of the Total Environment 628-629: 882-892.

[18] Crittenden, P. D. (1999): Aspects of the ecology of mat-forming lichens. - Rangifer 20(2-3): 127-139.

[19] Eldridge, D. J. (1996): Distribution and floristics of terricolous lichens in soil crusts in arid and semi-arid New South Wales, Australia. - Australian Journal of Botany 44: 581-599.

[20] Eldridge, D. J. (1999): Distribution and floristics of moss- and lichen-dominated soil crusts in a patterned Callitris glaucophylla woodland in eastern Australia. - Acta Oecologica 20(3): 159-170.

[21] Ester, M., Kriegel, H.-P., Sander, J., Xu, X. (1996): A density-based algorithm for discovering clusters in large spatial databases with noise. - In: Proceedings of the International Conference on Knowledge Discovery and Data Mining (KDD '96): 226-231.

[22] Eversham, B. (2015): Heathland Lichens. - Retrieved from https://www.wildlifebcn.org > sites $>$ default $>$ files (10.07.2019).

[23] Gheza, G., Assini, S., Passadore, M. V. (2016): Terricolous lichen communities of Corynephorus canescens grasslands of Northern Italy. - Tuexenia 36: 121-142.

[24] Gillespie, C. S. (2015): Fitting Heavy Tailed Distributions: The poweRlaw Package. Journal of Statistical Software 64(2): 1-16. URL http://www.jstatsoft.org/v64/i02/.

[25] Goldberg, N. A., Heine, J. N. (2014): Effects of canopy and leaf litter on the distribution of mat-forming terricolous lichens (Cladonia spp.) in northeastern Florida xeric scrub. Florida Scientist 77(2): 87-97.

[26] Gut1érrez, M., Pando-Moreno, M., Jurado, E., González-Rodríguez, H., Marmolejo, J. G., Mendoza, D. (2018): Non-random distribution of biocrust in a natural arid environment in the Northern Mexican. - Applied Ecology and Environmental Research 16(3): 2441-2451.

[27] Gypser, S., Veste, M., Fischer, T., Lange, P. (2015): Formation of soil lichens crusts at reclaimed post-mining sites, Lower Lusatia, North-east Germany. - Graph. Scr. 27: 3-14.

[28] Hinchliffe, G., Bollard-Breen, B., Cowan, D. A., Doshi, A., Gillman, L. N., MaggsKolling, G., de los Ríos-Murillo, A., Pointing, S. B. (2017): Advanced photogrammetry to assess lichen colonisation in the hyper-arid Namib Desert. - Frontiers in Microbiology 8: 2083.

[29] Hodgetts, N. G. (1992): Cladonia: a field guide. - Joint Nature Conservation Committee, ISBN $187370108 \mathrm{X}$. 
[30] Index Fungorum (2019): Retrieved from http://www.indexfungorum.org/ (10.07.2019).

[31] Irish lichens (2019): Retrieved from http://www.irishlichens.ie/pages-lichen/l-209.html (10.07.2019).

[32] Jackson, T. A. (2015): Weathering, secondary mineral genesis, and soil formation caused by lichens and mosses growing on granitic gneiss in a boreal forest environment. Geoderma 251-252: 78-91.

[33] Kéfi, S., Rietkerk, M., Alados, C., Pueyo, Y., Papanastasis, V. P., Elaich, A., de Ruiter, P. C. (2007): Spatial vegetation patterns and imminent desertification in Mediterranean arid ecosystems. - Nature 449: 213-217.

[34] Loppi, S., Boscagli, A., Dominicis, V. (2004): Ecology of soil lichens from Pliocene clay badlands of central Italy in relation to geomorphology and vascular vegetation. - Catena 55: $1-15$.

[35] Maestre, F. T. (2003): Small-scale spatial patterns of two soil lichens in semi-arid Mediterranean steppe. - Lichenologist 35(1): 71-81.

[36] Maestre, F. T., Bowker, M. A., Cantón, Y., Castillo-Monroy, A. P., Cortina, J., Escolar, C., Escudero, A., Lázaro, R., Martínez, I. (2011): Ecology and functional roles of biological soil crusts in semi-arid ecosystems of Spain. - Journal of Arid Environments 75(12): 12821291.

[37] Martínez, I., Escudero, A., Maestre, F. T., de la Cruz, A., Guerrero, C., Rubio, A. (2006): Small-scale patterns of abundance of mosses and lichens forming biological soil crusts in two semi-arid gypsum environments. - Australian Journal of Botany 54: 339-348.

[38] MycoBank Database (2019): Retrieved from http://www.mycobank.org/ (10.07.2019).

[39] Nelson, P. R., Roland, C., Macander, M. J., McCune, B. (2013): Detecting continuous lichen abundance for mapping winter caribou forage at landscape spatial scales. - Remote Sensing of Environment 137: 43-54.

[40] Nimis, P. L., Martellos, S. (2004): Keys to the lichens of Italy I. Terricolous species. - Le Guide di Dryades 1 - Serie Licheni I (LI). Trieste: Edizioni Goliardiche. ISBN 88-8817173-8.

[41] Ochoa-Hueso, R., Manrique, E. (2011): Effects of nitrogen deposition and soil fertility on cover and physiology of Cladonia foliacea (Huds.) Willd., a lichen of biological soil crusts from Mediterranean Spain. - Environmental Pollution 159: 449-457.

[42] Ochoa-Hueso, R., Hernandez, R. R., Pueyo, J. J., Manrique, E. (2011): Spatial distribution and physiology of biological soil crusts from semi-arid central Spain are related to soil chemistry and shrub cover. - Soil Biology and Biochemistry 43(9): 1894-1901.

[43] Ochoa-Hueso, R., Mondragon-Cortés, T., Concostrina-Zubiri, L., Serrano-Grijalva, L., Estébanez, B. (2017): Nitrogen deposition reduces the cover of biocrust-forming lichens and soil pigment content in a semiarid Mediterranean shrubland. - Environmental Science and Pollution Research 24(34): 26172-26184.

[44] Open Drone Map [Computer software]. (2019): Retrieved from https://github.com/ OpenDroneMap/OpenDroneMap.

[45] Osyczka, P. (2006): The lichen genus Cladonia (Cladoniaceae, lichenized Ascomycota) for Spitsbergen. - Polish Polar Research 27: 207-242.

[46] Panigada, C., Tagliabue, G., Zaady, E., Rozenstein, O., Garzonio, R., Di Mauro, B., De Amicis, M., Colombo, R., Cogliati, S., Miglietta, F., Rossini, M. (2019): A new approach for biocrust and vegetation monitoring in drylands using multi-temporal Sentinel-2 images. - Progress in Physical Geography: Earth and Environment 43(4): 496-520. https://doi.org/10.1177/0309133319841903.

[47] Pietrasiak, N., Johansen, J. R., Drenovsky, R. E. (2011): Geologic composition influences distribution of microbiotic crusts in the Mojave and Colorado Deserts at the regional scale. - Soil Biology \& Biochemistry 43: 967-974.

[48] Purvis, O. W., Coppins, B. J., Hawksworth, D. L., James, P. W., Moore, D. M. (1992): The Lichen Flora of Great Britain and Ireland. - Natural History Museum Publications, London. 
[49] Quantum GIS Development Team (2019): Quantum geographic information system. Open source geospatial foundation project. Retrieved from http://qgis.osgeo.org.

[50] R Core Team (2018): R: A language and environment for statistical computing. - Vienna, Austria: R Foundation for Statistical Computing. Retrieved from https://www.Rproject.org/.

[51] Rai, H., Upreti, D. K. (2014): Terricolous Lichens in India: Volume 1: Diversity Patterns and Distribution Ecology. - Springer-Verlag, New York.

[52] Rodríguez-Caballero, E., Escribano, P., Cantón, Y. (2014): Advanced image processing methods as a tool to map and quantify different types of biological soil crust. - ISPRS Journal of Photogrammetry and Remote Sensing 90: 59-67.

[53] Schindelin, J., Arganda-Carreras, I., Frise, E., Kaynig, V., Longair, M., Pietzsch, T., Preibisch, S., Rueden, C., Saalfeld, S., Schmid, B., Tinevez, J. Y., White, D. J., Hartenstein, V., Eliceiri, K., Tomancak, P., Cardona, A. (2012): Fiji: an open-source platform for biological-image analysis. - Nature methods 9(7): 676-682. PMID 22743772, doi:10.1038/nmeth.2019 (on Google Scholar).

[54] Sevgi, O., Makineci, E. (2005): Functions of lichens on disintegration and weathering of rocks (Likenlerin kaya parçalanması ve ayrışmasında işlevleri). - İstanbul Üniversitesi, Orman Fakültesi Dergisi, Seri B 55(2): 75-83.

[55] Sevgi, E., Yılmaz, O. Y., Özyiğitoğlu, G. Ç., Tecimen, H. B., Sevgi, O. (2019): Factors influencing epiphytic lichen species distribution in a managed mediterranean Pinus nigra Arnold forest. - Diversity 11(59): 1-21.

[56] Stoyan, D., Stoyan, H. (1994): Fractals, random shapes and point fields: Methods in geometrical statistics. - Chichester, UK: John Wiley \& Sons.

[57] Tilk, M., Ots, K., Tullus, T. (2018): Effect of environmental factors on the composition of terrestrial bryophyte and lichen species in Scots pine forests on fixed sand dunes. - Forest Systems 27(3): 1-12.

[58] Wang, X., Wiegand, T., Hao, Z., Li, B., Lin, F. (2010): Species associations in an oldgrowth temperate forest in north-eastern China. - Journal of Ecology 98: 674-686.

[59] Wiegand, T., Moloney, K. A. (2014): Handbook of spatial point pattern analysis in ecology. - Boca Raton, FL: CRC Press.

[60] Will-Wolf, S., Scheidegger, C., McCune, B. (2002a): Methods for monitoring biodiversity and ecosystem function-Monitoring scenarios, sampling strategies and data quality. - In: Nimis, P. L., Schedegger, C., Wolseley, P. A. (eds.) Monitoring with Lichens- Monitoring Lichens., Kluwer Academic Publishers, Netherlands.

[61] Will-Wolf, S., Esseew, P. A., Neitlich, P. (2002b): Monitoring Biodiversity and Ecosystem Function: Forests. - In: Nimis, P. L., Schedegger, C., Wolseley, P. A. (eds.) Monitoring with Lichens- Monitoring Lichens., Kluwer Academic Publishers, Netherlands.

[62] Yarranton, G. A. (1975): Population growth in Cladonia stellaris (Opiz.) Pouz. and Vezda. - The New Phytologist 75(1): 99-110.

[63] Zouaoui, S., Boudreault, C., Drapeau, P., Bergeron, Y. (2014): Influence of time since fire and micro-habitat availability on terricolous lichen communities in Black Spruce (Picea mariana) Boreal Forests. - Forests 5(11): 2793-2809. 